\title{
Practical Recommendation for the Use of Big Data in Strategic Management: Case Study of a Kazakh Telecommunications Company
}

\author{
Gulnara Z. Karimova ${ }^{1} \&$ Yevgeniya $\mathrm{Kim}^{2}$ \\ ${ }^{1}$ Business Communications, S P Jain School of Global Management, Dubai, UAE \\ ${ }^{2}$ Business Administration, KIMEP University, Almaty, Kazakhstan \\ Correspondence: Gulnara Z. Karimova, Assistant Professor Business Communications, S P Jain School of Global \\ Management, Dubai, UAE.
}

Received: July 7, 2018

Accepted: July 23, 2018

Online Published: August 5, 2018

doi:10.5430/jms.v9n3p88

URL: https://doi.org/10.5430/jms.v9n3p88

\begin{abstract}
This study analyzes the dynamics in the development and use of new, innovative technologies based on big data as they allow companies to expand their range of services, using large amounts of data, which in turn enables them to obtain economic benefits. Big data is often used as a tool for undertaking managerial tactical decisions rather than strategic. Using the practices of a Kazakh telecommunications company as an example, this study demonstrates how the potential of big data is limited to the decision-making tool and suggests how big data technology can improve the efficiency of the strategic management.
\end{abstract}

Keywords: big data, strategic management, Kazakhstan, telecommunications

\section{Introduction}

This study analyzes the dynamics in the development and the use of new, innovative technologies based on big data as they allow companies to expand their range of services, using large amounts of data, which in turn enables them to obtain economic benefits. This study points to the broader potential of big data and aims at developing practical recommendations for efficient application of big data in strategy rather than merely as a tool for operational decision making. The study uses a Kazakh telecommunications company as an example, which demonstrates the limited usage of big data as a tool rather than as a strategy. Such recommendations can improve the efficiency of strategic management and disclose new potentials and applications for big data technology.

The purpose of the study is to develop a set of theoretical and methodological measures and practical recommendations aimed at efficient use of big data technology as a strategy in Kazakh telecommunications companies. To achieve this goal, the following research objectives are advanced:

- To examine the scientific and methodological approaches to strategic development of telecommunications;

- To consider the characteristics of information technology and strategic development of the major players in the field of telecommunications;

- To analyze the strategic audit of telecommunications and to assess the performance of big data at work using the example of a Kazakh telecommunications company;

- To identify problems and directions of development of big data in telecommunications in Kazakhstan.

- To identify differences in using big data as a strategy and as a managerial tool.

The first section discusses recent developments of big data technologies. The following part introduces the use of big data in strategic management. In the subsequent section, the case study of a Kazakh telecommunications company (referred further as 'the company') is presented. Analysis and results of the empirical study of the telecommunications industry in Kazakhstan follow. In the conclusion of the study, the recommendations for increasing the management efficiency through the utilization of big data technology as a strategy are proposed. 


\section{Literature Review}

\subsection{Strategic Management}

The term 'strategic management' was coined in the late 1960's to early 1970's. The ideas of strategic management and development of business strategy are reflected in the works of many scientists (Ansoff, 1972; Hatta \& Shendel, 1972; Irwin, 1974; Thompson et al., 2007). The main idea, which reflects the essence of the transition from operational to strategic management, was dictated by the need to transfer the focus of the top management's attention to the environment, to adequately and timely respond to changes occurring in it.

If we go by the historical definition of the word 'strategos, ' which translates from Greek as "the art of the generals," it makes sense for the senior management to determine the path of movement for the company. Strategic decisions are "broad in scope, long-term, and risky" (Power, 2015, p. 2). They are more complex and unstructured than administrative or operational decisions (Strategic Management, 2017). Strategy considers external and internal environment, builds sustainable competitive advantage and enhances company performance (Thompson et al., 2007).

In significantly large and mature companies, that have passed the period of formation and development, and accumulated considerable experience in the strategic planning process, three main elements can be identified as fundamental: formulation of goals and objectives, development of strategies and tactics, and evaluation of implemented strategy. Each element is accompanied by research and engagement to the decision-making process. In the current context of globalization and development of information technology, the decision-making process is becoming more complex. The ability to utilize technology in the decision-making process and management strategies, to adapt quickly to the environmental and market changes, becomes a competitive advantage. Today, managers can measure and thus, know more about their businesses, and directly translate that knowledge into improved decision making, relying on big data.

Big data is mainly used as a tool for improving the decision-making process and increasing the efficiency of operational tasks. The potential for big data to serve as strategy is yet to be developed and to continue this discussion; we can move onto analyzing the term 'big data.'

\subsection{Big Data}

Some describe 'Big data' and 'fast data' in terms of specific dimensions, such as volume, variety, volatility, and velocity (McAfee \& Brynjolfsson, 2012; Power, 2015). Power (2015, p. 2) explains,

Data variety refers to the increasing number of formats of digital data. Data velocity refers to the increasing speed of data generation, data processing, and data use. Data volume refers to the increasing number of bytes of data stored on various media. Data volatility means 'data flows can be highly inconsistent with periodic peaks.' Variable data has a widespread, is complex and from diverse sources. Variability also means changeable.

The concept of big data includes a set of approaches, methods, and tools for the processing of vast volumes of information data (structured and unstructured) for perceived human results that are effective in the conditions of continuous growth, allowing distribution of information on a variety of nodes computing information network. The concept of big data implies not 'lots of data' but a special type of internal relations and structure of data, both 'multi-structured' and 'unstructured' (Semerkin, 2015). Big data allows managers to explore large amounts of data and obtain extremely valuable information for the business that in turn helps to make decisions.

Studies show that big data performs three types of tasks:

1. The management and storage of vast amounts of data that other databases cannot efficiently use;

2. The organization of management and storage of unstructured information, which consists of different types of data (video, text, images, etc.);

3. Analytical work with unstructured information, generate analytical reports and implementation of predictive models (Gantz \& Reinsel, 2013).

Big data is now widely used in telecommunications in various areas. The concept of 'telecommunication' acquires different meanings depending on how the resource is used. Network communication resources are divided into three types: information, hardware, and software. According to Marder (2006), telecommunication is not just a mechanical unification of telecommunications with information technology; instead, it covers broader aspects. Big data is used in telecommunications in the following ways: 
1. The use of search engines:

A large number of customers have free accounts (of a total only about $5 \%$ are paid). Advertising placement and contextual advertising carry a lot of information. Personification in Big data allows one to keep track of each user, create online patterns and compare them with other users (ten to fifteen millions of users). It is possible to identify each client and offer him/her the desired result (Belov, n.d.).

2. The use of mobile communication:

The data network can be used to construct the most accurate forecasts, as well as for the development of realistic and most plausible models of towns and cities. The data obtained from the cellular companies are the most reliable; which is commonly used for the formation of urban environment databases, from which models of urban development are built. For example, the company "Telefonica", using big data analysis, offers solutions for the formation of various city databases in the UK, Spain, Germany, Brazil, Argentina, and Mexico. The Russian company "MegaFon" has "geo-service" function that gives an extremely accurate and timely picture of the life of Moscow and other large cities (Rostnikov, n.d., Belov, n.d.). Information obtained using big data is more extensive and cannot be obtained through the census of the population or other theoretical calculations. To construct, for example, nationally representative population models, tens of thousands of interviews must be conducted, while "MegaFon" possesses data the magnitude of which is greater than the amount of information produced by the census.

Big data trend at the present stage of development has a promising direction for the communications industry and Kazakhstani telecommunications market endeavors to follow this direction (Belov, n.d.).

\section{Methodology}

To develop a set of theoretical and methodological measures and practical recommendations aimed at efficient use of big data technology as a strategy the case study of a Kazakh telecommunications company was used. "Case studies involve in-depth, contextual analyses of similar situations in other organizations, where the nature and definition of the problem happen to be the same as experienced in the current situation" (Sekaran \& Bougie, 2010, p. 30). Carefully analyzed data received form a Kazakh telecommunications company may help to obtain some clues as to the factors that play an important role in implementing and using big data for strategic management.

So far, we have explored the concepts of strategic management and big data. In the next sections, we will look at Kazakh telecommunications environment.

\subsection{Directions of Development of the Telecommunications Market in Kazakhstan}

The basic trends of the telecommunications services market in the Republic of Kazakhstan are presented in one of the essential commands of the country development and are reflected in the national development strategy of Kazakhstan through the growth of Information and Communication Technologies (ICT).

ICT received such attention because they

- $\quad$ help to achieve efficiency in management and increase productivity;

- $\quad$ provide new opportunities for the export of software and innovative technologies;

- $\quad$ expand depth and breadth of services in the field of ICT;

- $\quad$ provide information to all sectors of the economy;

- $\quad$ enhance the capacity to provide primary health care advice;

- $\quad$ expand the possibilities of distance education; and

- $\quad$ improve the service quality provided by the state.

Since 2004, in the Republic of Kazakhstan, liberalization (withdrawal and the easing of restrictions) of the telecommunications market took place to create a competitive environment, which led to a rapid saturation of the market with quality and affordable services. The following are the key segments of the telecommunications market in the Republic of Kazakhstan:

- Mobile communications ("Kcell," "Kar-Tel” (Beeline), “Altel," "MTS” (Tele2));

- Fixed telephony (Kazakhtelecom of DUCAT (Arna), "TransTelecom," "KazTransCom," GC "VimpelCom" (SA-Telcom, TNS-plus), Sky Silk);

- $\quad$ Services operators (Kazakhtelecom, KazTransCom VimpelCom (SA-Telcom, KZ-Trans), Transtelekom); 
- Data transmission and the Internet ("Kazakhtelecom," "KazTransCom," "Transtelekom" of DUCAT (Arna), Astel, SC "VimpelCom" (SA-Telcom, 2DAY-Telecom));

- $\quad$ Pay-TV services (Alma TV, Aina TV Company “Sekatel," “Kazakhtelecom,” ICON, Digital-TV).

- As a result, in the telecommunications market of Kazakhstan, eleven operators provide long-distance and/or international telephone services; four significant operators offer mobile services; more than four hundred operators provide services for a local telephone communication network and Internet access, and six major operators provide Pay-TV.

The primary share of telecommunications market belongs to mobile connections (40\%). Kazakhstan telecommunications market is one of the most developed and most competitive in Central Asia. In terms of network readiness, according to the Networked Readiness Index of 2014 , Kazakhstan was on the $38^{\text {th }}$ place (out of possible 148), an improvement of six points when compared to the year of 2013 (BRK Analytics, 2014).

The structure of the telecommunications market in Kazakhstan according to the amount of income is shown in Figure 1.

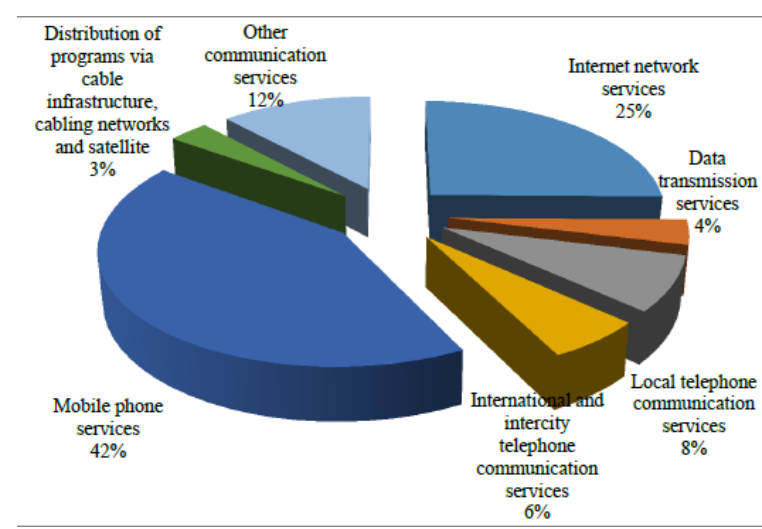

Figure 1. Structure of the telecommunications market in Kazakhstan

Retrieved from http://stat.gov.kz

This market has a significant long-term growth potential in sectors such as information, communications, mobile data services and business-to-business (B2B) services. According to the Kazakh Statistics Agency's report, the telecommunications market in Kazakhstan grew in 2014 by $4.6 \%$ compared to 2013 (See http://stat.gov.kz).

Figure 2 clearly shows the evolution of revenues in the main segments of the telecommunications sector of the market, as well as areas of stagnation and growth point of Kazakhstan communications sector.

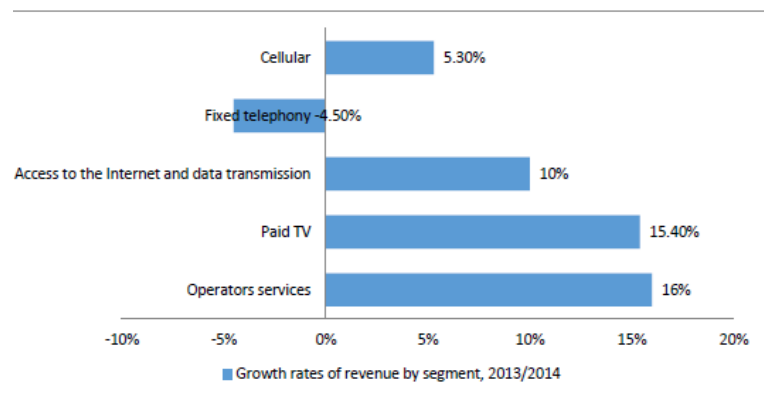

Figure 2. The evolution of revenues

Retrieved from http://profit.kz/news/ 
Growth in revenues from mobile data in 2014 in Kazakhstan increased by almost $50 \%$ in comparison with 2013, thereby ensuring the overall growth of the entire cellular market. One of the factors of income growth in the volume of services from mobile data was the increase in the number of mobile Internet subscribers, who started to transmit data on smartphones. In 2014, iKS-Consulting estimated that the number of subscribers has exceeded 4.5 million, which is two times more than in 2013. This development in Kazakhstan LTE network (just one ALTEL operator) has had a significant impact on the market. These 4G network users expect high data transmission speeds. Currently, mobile communications in Kazakhstan is provided by four mobile operators. Their share of the market is shown in Figure 3.
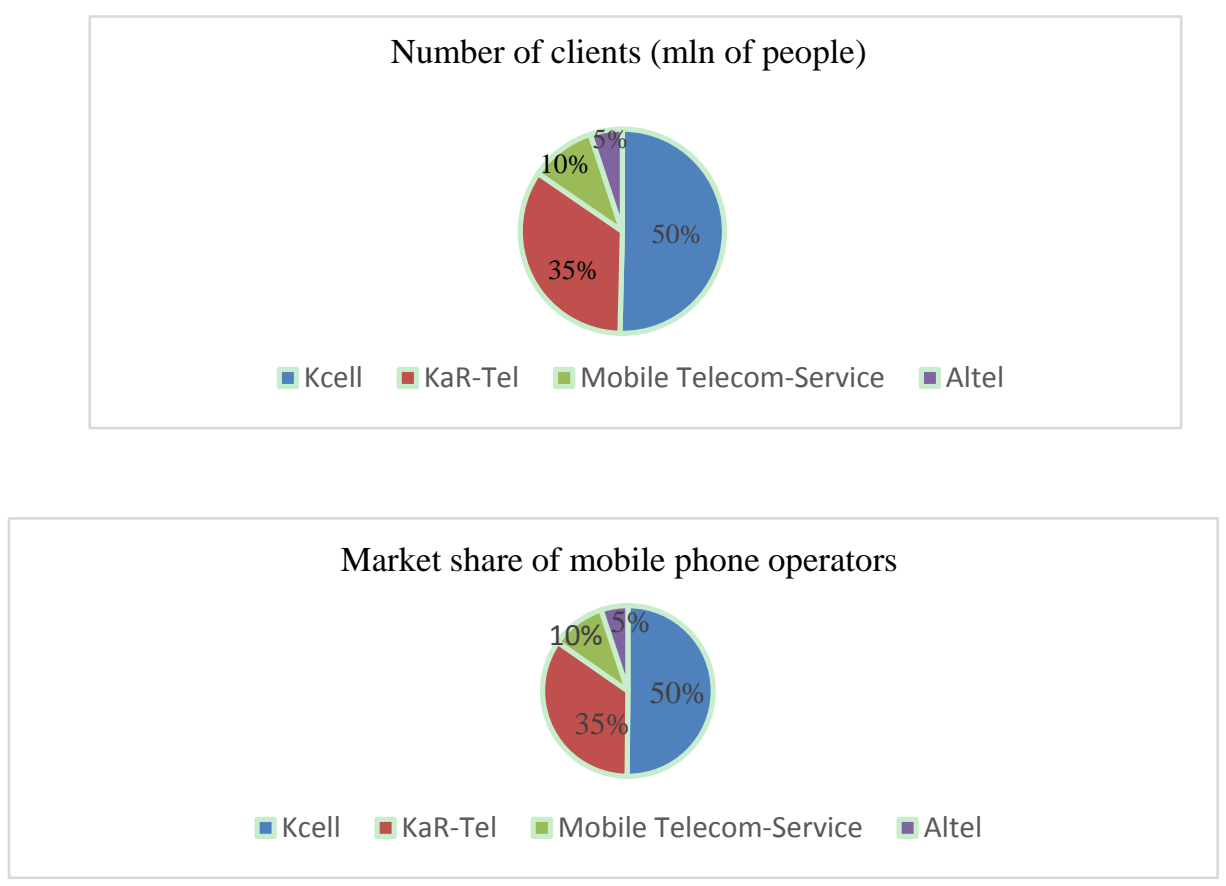

Figure 3. The structure of telecommunications market

Retrieved from http://profit.kz/news

According to analysts, the significant trends in the upcoming years in the development of the market will be as following:

- Attracting investments to the sector (small amount to more than $2 \%$ of the total volume of economic activity);

- Developing of transit potential (Kazakhstan passes through transit information channel);

- Introducing cloud computing (up only $2 \%$ of the total IT services);

- Maximizing the market reach of Internet access services;

- Attracting subscribers from other consumer segments that were previously assessed as unattractive (data, business services);

- Introducing new information technologies, including Big Data.

Although, telecommunications have the potential for innovative growth there are a few challenges in its development path.

\subsection{Problems of Development and Risks in the Telecommunications Market}

In 2014, the active development of Kazakhstani data market led to the fact that operators have faced the Kazakh media "connectedness," which has resulted in a massive difference between the income growth rate and the network traffic growth rate. 
There is a weak domestic demand for innovative information technology from citizens and businesses alike due to the high prices related to the innovative technologies that are deterrent to the development of local telecommunications companies. Also, the investment activity of businesses, concerning the growth of e-business and e-commerce is reduced. Moreover, domestic web resources are scarce and so is original Internet content in the Kazakh segment. Another problem related to the development of the telecommunications industry is the lack of qualified specialists in Kazakhstan. The growth of wages in the sphere of information technologies is higher than the growth of labor productivity, which reduces the competitiveness of the telecommunications industry in foreign markets. As a result, telecommunication companies have to attract international specialists, hire experts from related industries or make additional training costs to meet the demands of the market.

Ernst \& Young Consultancy Group revealed the risks of the telecommunications sector:

- The absence of quick response to rapidly changing customer expectations;

- The need to redistribute the tariff structure of mobile operators from voice to data communications;

- The lack of the legal certainty on the part of governments and regulatory bodies for the new market structures;

- The abundance of uncertainties regarding the obligations of operators in the field of the fight against terrorism;

- The problems related to security and privacy in the new areas of services, such as cloud computing and mobile applications;

- The lack of certainty of operators in return on investment, as the tight control of investment limits the willingness and ability of operators to introduce new technologies and build new services;

- Vague terms used for mergers, acquisitions and partnership strategies that are essential for success in emerging market segments, such as mobile advertising and cloud computing;

- The lack of synchronization and organizational flexibility between operations divisions and branches to maximize economies of scale.

The direction of the development of telecommunications industry of Kazakhstan, both in the domestic market and in foreign markets, depends on problem-solving and overcoming possible risks.

\section{Analysis and Discussions}

\subsection{Suggestions for the Implementation of Big Data}

The global trend based on the rapid growth of data dictates to developed countries - which are a step or even two ahead of Kazakhstan - the implementation of efficient information technology in telecommunications.

In 2014, the Kazakhstani industry embarked on the development of e-commerce and big data. Today, the necessary infrastructure for the development of the Internet and e-commerce is growing. In Kazakhstan's e-commerce market, there are over three hundred online stores and other market participants. To study the implementation of big data technologies in Kazakhstan, Laboratory "Big Data" was created by JSC "National Information Technologies." This laboratory, since 2015, is analyzing the effectiveness of the user profiles of e-Government portals. The main sources of data analysis are Public Service Centers, e-Government portal, electronic applications of citizens through e-mail services, SMS-messages and phone calls to the Unified Contact Center, and social networking information. Currently, the e-Government portal has accumulated up to fifteen terabytes of information. The objective is to learn how to position the e-government and public services more accurately for the several target audiences of the population. This database should anticipate the different behavior of portal users. For example, if a child was born, the state database will suggest the list of documents that parents need to obtain such as the birth certificate of the child; registration into clinics or hospitals; applying for benefits, and even automatically getting placed into a kindergarten. Thus, the idea of Government for Citizens is planned to be implemented through more data (Zhukenov, n.d.).

A few major suggestions to solve existing problems in the telecommunications industry in the Republic of Kazakhstan are as follows:

- The optimization of costs, including by collaborative use of the infrastructure;

- Further development and use of more efficient technologies that enable operators to derive higher returns at lower cost;

- "Monetization" of the traffic, which allows for an increase in the volume of services to achieve the optimal balance of price and volume; thus, bringing in additional revenue. 
It should be noted that the mobile operators being in a constant fight against competitors, invest in the network trying not to lose to their direct competition in quality and in generating traffic. This investment is done by introducing Over-The-Top (OTT) services (any service that provides a product over the Internet and bypasses traditional distribution, (Technopedia, n.d.)) that are becoming more popular, eventhough it does not generate any revenue. It is necessary to find a new economic model that will reduce margins and optimize costs of operator services under the influence of traffic of OTT services. Operators need to radically revise approaches to interaction between the carriers, moving to partnership agreements as competitive strategies. Such joint efforts will enable companies to confront external competition effectively. Joint construction and use of the infrastructure will significantly reduce capital costs. This is especially important for mobile operators which declare their readiness to develop big data technologies.

The prospects and strategy for the future of the telecommunications market in Kazakhstan and its major players consist of data transfer and the implementation of big data, and it is important to recognize the market trends right now. The introduction of information technologies such as big data focused on the need for transformation of the market paradigm should be incorporated in the strategies of major telecommunications market players.

\subsection{Strategic Development Plan and Big Data in a Kazakh Telecommunications Company}

In its development strategy, a Kazakhstani telecommunications company aims at growth and cash flow generation. To achieve this aim, the company's priorities are the use of economies of scale, cost optimization, and capital management - which require high expenditure. The company also pursues such strategic goals as the establishment of strong leadership and cultivation of responsible business. Also, the company strives to optimize the organizational structure, providing clear oversight responsibility and chain of command to maintain a strong system of corporate governance, which ensures transparency, integrity, and accountability of the entire work and to promote sustainable development as a way of life. Next, the realization of these indicators is analyzed with reference to the practical implementation of big data.

Business Intelligence (BI) is used in the company as a set of applications and technologies for gathering, storing and analyzing data to help make the best and right decisions in the management, record keeping, conducting data analysis, planning, forecasting, statistical analysis, finding regularities (hidden), etc. The main function of BI is an in-depth analysis of detailed data on the subjects' area and data storage. The use of unique information program applications based on big data, which have their own methods of handling and storage, allow the interested parties to turn them into knowledge/information. This acquired knowledge/information can improve the efficiency of the company's activities and enable them to receive certain benefits within the company and on the external market.

The first step in BI of the company is preparing data for analysis:

- Performing data extraction from information sources;

- Data cleaning and transformation of data into a standard format;

- Loading the transformed data into the data warehouse;

- Creating Meta descriptions of the data (structuring data understandable to the end user).

It is understandable that today, the company has a significant amount of information, which is mainly composed of internal information: central accounting, finance, human resources, corporate governance, information about users, and such resources as "Mobile Internet."

The second step comprises of software and analytical tools:

- Software generates queries and reports that allow one to visualize the data warehouse, produce analysis and reports;

- Software tools for online analytical processing, which allows one to investigate the data on different types of measurements (date, time, place, units, organizational, etc.);

- Universal analytic applications organized around a specific subject area with the target analysis and models (analysis and sales forecast, budget and strategic planning, risk analysis and trends, etc.).

In these cases, the following data analysis techniques are used: Data mining (clustering, search attributes, and feature extraction) allowing the compilation of the data into specialized libraries and data banks. The individual test results are recorded in forms as shown in Figure 4. 


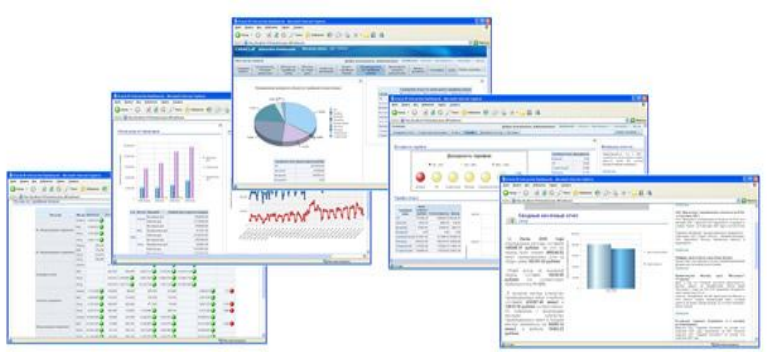

Figure 4. Example of the results of analysis, 2015

Retrieved from, https://www.kcell.kz

Using its systems the company can observe what is happening with the subscribers, with revenues from sales to determine the situation in the regions, to trace the geography, etc. It allows companies to make the right management decisions. Using big data the company personalizes its approach to each client in real time, regarding tariffs and services. The implementation of this platform, in principle, allowed the company to form the nucleus, which enables one to get started working with big data. Big data is used by the company primarily in analytical work as one of the elements of the analysis program. Used in BI management, which aims at the analysis of the materials, their results allow the management to take correct and effective measures that directly, from the experience of the telecommunications companies, increases customer satisfaction indicators, thus, reducing their outflow. Also, the analysis improves the operational efficiency of the enterprise, due to the detection of fraud schemes and sources of losses, as well as an opportunity to address them timely.

big data tools are used to target the company's marketing activities to enable promotion of its core products. Using this model, enhances advantages for the brand, providing such features as fight against fraud, creating personalized campaigns, and targeted advertising. Used to manage the outflow of the subscriber base, it allows us to analyze the running events, planning of network development and its construction. These technologies enable business analysts to build a variety of predictive mathematical models and identify the most effective ones.

It is common for companies in the telecommunications sector to apply readily available software solutions, creatively adapting it to the realities of specific businesses. Similarly, a Kazakhstani telecommunications company operates on the basis of a business solution 'Pontis'. The model on which the company has been working with 'Pontis' involves profit sharing, which allows it to avoid a huge investment in the platform and business model. In this case, "the vendor" gets from the project part of the company's income. Rightly so, if the company had no "vendor" platform, there would be no income generated from this direction. It is quite efficient and more appropriate for such enterprises as a Kazakhstani telecommunication company.

Promising directions for the development of big data at the company are:

1. Developing personalized targeting for providing suggestions (via a mobile app, SMS or USSD and payment terminals);

2. Improving the quality and accuracy of forecasting;

3. Managing the quality of service for both its own network and for subscribers;

4. Providing security through fraudulent schemes

The company website contains a line called "Speak-up," which is focused on its commitment to responsible business conduct to prevent unethical business practices. With the help of a web portal - Speak-Up Line - customers can safely and confidentially inform the company about any violations. It is also stated that "the portal is managed by an independent party and provides a high level of privacy."

In addition to this, the anti-corruption policy is based on the company's devotion to highest standards of business conduct. The company takes responsibility for its actions, guided by a number of values and principles referred to in the corporate policy.

By implementing big data, the company relies on the fact that the potential of information technology should be based on the necessity to radically change the perception of service quality. It is also believed that these technologies will enable companies to optimize costs. Now, the company is expanding its network across the country covering 
new territories. The use of big data is justified by the fact that in recent years, telecom has started losing its profitability, and there is a need to improve business efficiency radically. In general, the company celebrated the overall business focus that is aiming at investing in IT. Investments in such projects as big data are significantly expensive, but without them, telecommunications companies typically do not survive in its market. The company's Code of Conduct considers the supplier procurement and capital investment, which includes equipment and services related to the creation, development, and maintenance of mobile networks, as well as IT infrastructure. The Code of Conduct also stresses the importance of sustainability management throughout the supply chain to ensure the implementation of its own obligations in the field of sustainable development. The company defines some of its unique features, which will enable the Company to become attractive to investors (see Figure 5).

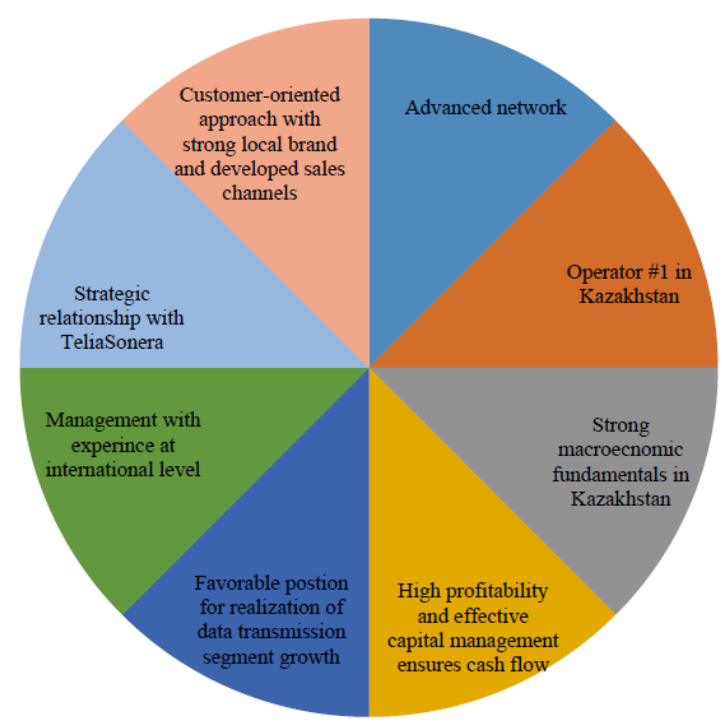

Figure 5. Advantages of the investments

Retrieved from http://investors.kcell.kz

It can be concluded, that the analysis of the strategic development plan has shown that one of the main strategic directions for the development of the company is to ensure its growth and leading position in the telecommunications market through the expansion of basic services. Expanding global information data and increasing competition in the market requires the company to introduce new technologies, including those of big data. To establish strong leadership, companies need to strengthen the culture of responsible business, optimize the organizational structure and maintain a strong system of corporate governance. All these can be achieved through the introduction of modern IT technologies.

Currently, the main problems hindering the expansion of big data technologies in the company is low demand from the market and the lack of adequate investments since tools such as big data are expensive. There is also a dearth of experienced professionals, marketers, and analysts possessing knowledge of working with these technologies. 


\subsection{The Prospects for the Development of a Kazakhstani Telecommunications Company}

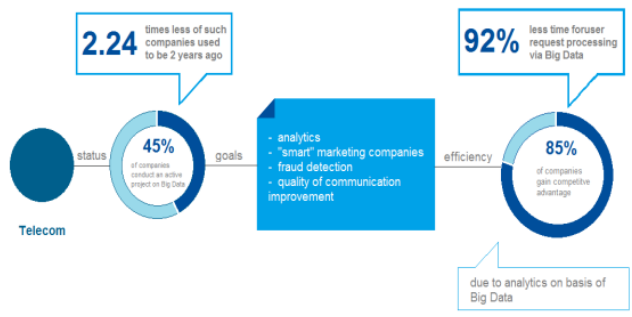

Figure 6. General trends and performance indicators in telecommunications industry (Gartner)

According to Gartner, to determine the prospects for the development and efficient use of big data by the company under investigation we are going to analyze the main indicators of big data on market operators. General trends and performance indicators in the context of the industry are shown in Figure 6.

The given success of the service provider is achieved by using four basic methods of big data to improve the internal workings of the company and services to external customers (Kolesov, 2015):

1. Precise marketing includes offering new tariff plans, additional services, payment terminals as well as targeted products and services to those consumers who are most willing to acquire them;

2. Customer experience management implies quality control services for the client to prevent the outflow of users;

3. ROI-based Network Optimization and Planning - optimization of the internal processes of the operator to maximize ROI guarantees as soon as possible, by objective factors and views of consumers;

4. Data Asset Monetization - monetizing information assets - sale of the equity in the projects available to the data controller, to its partners.

Let us consider the experience in the field of telecommunications, based on the prediction of the number of 'disconnect' and 'connect' to networks and services, which proposes the automatic development of models and their implementation in the mobile communications companies on the basis of the use of STATISTICA Enterprise products and of STATISTICA Data Miner. The Data Miner project is stored in the form of a network of nodes in the STATISTICA Enterprise, which is updated to the new data. Introduced into production, this model monitors the STATISTICA Enterprise. With the help of MAS server, the predicted values are compared with the actual values. If the poor performance of the model is observed and the remains become large, then alarm occurs on Shuhart map and MAS reports it. As a result, the model is going to be rebuilt or updated (Figure 7).

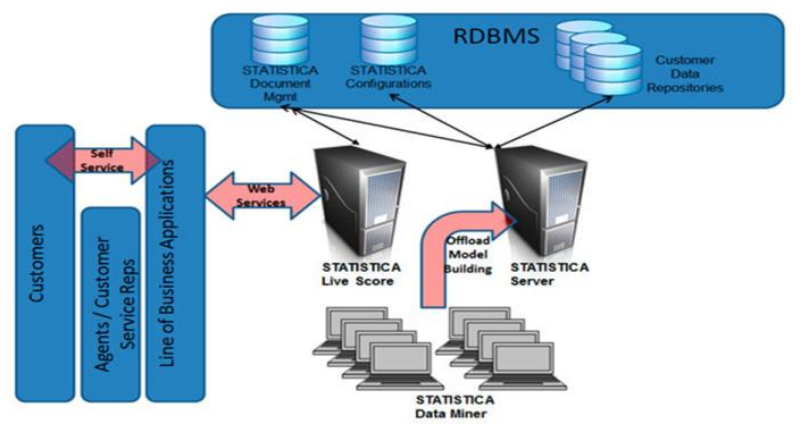

Figure 7. STATISTICA live score

Retrieved from http://statsoft.ru/academy/courses/general 
Information technology to be applied by the company, used for collecting, storing and processing more data usually include the following groups: Hardware, Software, and Services. The most appropriate approach is to select the next program (software) for data processing:

- $\quad$ Structured Query Language (SQL) that allows one to work with large databases. With the help of SQL, one can create and modify the data, while the control data set to be involved in a system should be explicitly designed for database management.

- NoSQL - stands for "not only SQL," provides a number of approaches that focus on the implementation of large databases that are used in relational databases. Typically, they are used for structuring the constantly changing data. NoSQL is recommended for the collection, processing, and storage of information in social networks of the Internet.

- MapReduce model is designed for the distribution of computing. Usually, it is used for parallel computing, which is conducted on very large-volume data sets (petabytes or more).

- SAP HANA model is considered high-efficiency New SQL system, which serves as a platform for the processing and storage of data. This system allows providing high-speed search and querying processing. Another feature of the SAP HANA is that it allows simplifying the system landscape, thereby reducing costs of service support for analytical systems.

Thus, the proposed model, the software, service equipment and services will permit the company to form a comprehensive platform for the collection, processing, storage and analysis of large data. With the introduction of these technologies, it is necessary to know that you can implement these yourself, or you can use the services of specialized companies. For example, such companies as Microsoft, HP, and EMC offer services related to the development of the big data solutions.

In conclusion, the research has detected some positive and negative aspects in the development of the telecommunications market in Kazakhstan on forming new management and production of information technology for the efficiency of the companies operating in it. It is a necessary and vital step towards the effectiveness of the means of implementation of big data, which eventually should help businesses remove barriers (legitimate) and increase profitability.

The system analysis of the process of development and evaluation of models of big data allowed predicting and identifying the causes of resistance to change occurring at various stages of the implementation of its elements.

Implementation of big data will enable the company to store and manage their own databases effectively and conduct a thorough analysis of the accumulated information. Through big data, the company will be able to retain existing customers by providing them with more data services and attract new customers. To achieve this, companies need to carry out the segmentation of its customers - constantly analyzing their traffic and defining their social identity. All these actions focused on big data will increase the number of customers and as a result, receive the planned revenue that will allow the company to maintain its leading position in the telecommunications market of Kazakhstan and to ensure their competitiveness.

\section{Conclusion}

This study found that the results in the field of information and communication, based on the example of scientific and applied research, create a solid foundation for the emergence of a new branch of knowledge in the information industry. Today, information services industry is developing successfully, and it has its own automated data processing technology. It is characterized by unprecedented scale and quality indicators in the field of telecommunications, allowing millions of consumers to receive a wide range of possibilities.

For the development of telecommunications and to ensure the effectiveness of the major players in this market, innovative information technology and modern models of integrated strategic management should be introduced, which will allow large companies in the telecommunications market to ensure its competitiveness in the regional and international markets.

The growth of the ICT sector in Kazakhstan is carried out according to the State Program of Accelerated Industrial-Innovative Development (PAID), indicating that this sector is recognized as one of the priority sectors and this sector will give rise to the "economy of the future, which in the next fifteen-twenty years will play a dominant role in the global economy" (Decree of the President of the Republic of Kazakhstan on the State Program on Forced Industrial and Innovative Development of the Republic of Kazakhstan for 2010-2014, 2010). 
The study also found that in Kazakhstan there is a problem in data supply to the domestic market and the informational transit potential of the country. Today, through the territory of Kazakhstan in the direction EuropeAsia from the existing level of global information flow, passes the flow at speed of about $50 \mathrm{Gbit} / \mathrm{s}$. This figure in 2030 will increase to $537 \mathrm{Gbit} / \mathrm{s}$, and in 2050 upto $1,750 \mathrm{~Gb} / \mathrm{s}$. For the development of transit potential, Kazakhstan needs to create a data center (in 2014, there were twenty-four data centers and one laboratory, in total, whose services were used by more than 14.5 thousand clients).

The major hurdles for the players in the Kazakhstan telecommunications market are majorly traditional: security, the high cost of information technologies and equipment for its introduction, difficulties in integration with the existing system operators, as well as a shortage of professional staff.

The primary option to generate additional income from big data is an analytical solution, which should be aimed at the integration of existing IT infrastructure that enables one to quickly create new approaches to optimize business activity (attracting massive customer data). It is possible to increase profitability by utilizing big data's analytics potential, for example, by reducing the time of construction of predictive models from a few days to a matter of minutes, thus, increasing the efficiency of the operator to retain subscribers. In addition, analytical products big data permit to reveal customers' values, which is based on their activities and expectations, considering changes in the market, and in advance can offer them the right products. That also usually leads to an increase in the profitability of the services of mobile operators and reduces IT expenses.

Analogical findings were reviled in the study conducted by researchers in the telecommunications industry in Oman (Al Jabri, et al., 2017). Using the cases of the two main telecommunications operators the authors found out that despite challenges such as the lack of clear big data strategies, security concerns and the need for workforce reskilling, the growth potential of big data analytical tools is evident. The findings derived from analysis of two Omani operators have striking resemblance with the results of the study of a Kazakhstani telecommunications company.

- "Although both operators demonstrated a good realization of big data and BDA they failed to articulate the expected value from BDA initiatives;

- Availability of the right skill to deal with BDA was an obstacle for both organizations;

- Infrastructure readiness in both organizations was another obstacle to BDA implementation;

- The quality of the existing data and the weak integration between data sources did not allow the organizations to see the intended value of the initiative" (p. 12).

In Kazakhstan, telecommunications have significant potential and a sufficient market volume required for the application of analytical solutions of big data on customer experience management. It should continue to actively develop this area, as it will ensure efficient development of the telecommunications market in Kazakhstan and its key players.

\section{References}

Al Jabri, A. H., Al-Badi, A. H., \& Ali, O. (2017, January-March). Exploring the usage of Big Data analytical tools in telecommunication industry in Oman. Information Resources Management Journal, 30(1).

Aldoshin, O. (n.d.). Interesting times for telecommunication are coming. Interview by Computerworld.kz. Retrieved from http://www.computerworld.kz/podcast/8667/

Analytical market overview for 2014. (n.d.). Statistics agency of Republic of Kazakhstan website. Retrieved from http://www.stat.gov.kz/

Ansoff, H. I. (1972). Strategy as a tool for coping with change. Journal of Business Policy, 4, 3-7.

Bati, C. (n.d.). Big Data. TAdviser. Retrieved from www.tadviser.ru/index.php

Belov, I. (n.d.). How to recognize and apply large data in business? Overview of the world and domestic experience. Retrieved from http://www.billing.ru/

Bleiher, V. M., \& Kruk, I. V. (n.d.). Dictionary of phsychiatric terms. Retrieved from http://www.persev.ru/insayt

Bnews.kz. (n.d.). Zerde national information and communication holding. Retrieved from http://www.bnews.kz

BRK Analytics. (2014). Overview of trends in the telecommunications industry. Retrieved from http://wiev-IT

Chernenko, S. (2015, January 21). IKS-Consulting in Kazakhstan: Market Overview. Retrieved from http://www.profit.kz 
CiscoSystems. (2002). Unified Networks Technology Guide (3rd ed.). Moscow, Russia: Williame.

Data transmission systems and channels. (n.d.). Retrieved from http://davaiknam.ru/texts/1001/1000751/1000751_html_5e3d5bfe.png

Demina, Y. V. (2011). Management efficiency and ways to increase it (Unpublished doctoral dissertation). Omsk state technical university, Omsk, Russia.

Dorot, V. L. (2001). Explanatory dictionary of modern computer vocabulary (2nd ed.). Saint Petersburg, Russia: BHV-Saint Petersburg.

EPSIRating: Analytical Review. (2014). Retrieved from http://www.profit.kz

Ernst \& Young. (n.d.). Analytical overview for 2014. Retrieved from http://consulting-company.ru/ey.com

Gantz, J., \& Reinsel, D. (2013, February). THE DIGITAL UNIVERSE IN 2020: Big Data, Bigger Digital Shadows and Biggest Growth in the Far East - United States [IDC Country Brief].

General Electric. (n.d.). Principles of GE. - Internet Resources. Retrieved from http://www.ge.com/ru/evalue.htm

Goldstein, G. (2003). Strategic management: Tutorial (2nd ed.). TRTU.

IDC Digital Universe. (n.d.). Retrieved from http://www.idc.com

Informatics Point. (n.d.). Concept of telecommunication technologies. Retrieved from http://www.informaticspoint.ru/forpois-653-1.html

Information systems and technologies in the organization of management activity of the enterprise. (n.d.). Retrieved from http://www.puremanager.ru/pobds-590-1.html

Information technology, information systems. (n.d.). Retrieved from http://sergeeva-i.narod.ru/inform/page2.htm

Investments advantages. (n.d.). Kcell. Retrieved from http://investors.kcell.kz/ru/article/show/1619/

Irwin, P. H. (1974). Towards Better Strategic Management. Long Range Planning, 7, 64-67. https://doi.org/10.1016/0024-6301(74)90135-6

Ivanova, O. N. (2006). Telephony in dates [PowerPoint slides]. Retrieved from http://www.myshared.ru/slide/950047/

Khan, A. (2014, October 1). Analytical review. Retrieved from http://www.profit.kz

Kolesov, A. (2015). What Big Data can give to customer? PC Week. Retrieved from http://www.pcweek.ru/idea/article/detail.php?ID=174785

Koptelov, A. K. (2007). Strategic management of the telecommunications company on example of a balanced scorecard. Mobile telecommunication, 4.

Kryukov, I., \& Shadrin, A. (2004). Balanced scorecard in an integrated quality system (6th ed.).

Lavina, T. A., \& Robert, I. V. (2006). Explanatory dictionary of terms of the conceptual apparatus of informatization of education.

Lebedev, A. I. (2011). Classification of managerial innovations in the activities of organizations in the telecommunications area of the economy. Analytical magazine RISK-M, 3.

Lyasko, V. I. (2005). Strategic planning of enterprise development: Textbook for high schools. Ekzamen.

Madorskaya, Y. M. (2011). Improving accuracy and reducing scheduling time in software project management processes, pp. 92-99. Saint Petersburg, Russia: Renome.

Marder, N. S. (2006). Modern telecommunications, p. 384. Moscow, Russia: IRIAS.

Markova, V. D., \& Kuznetsova, S. A. (1999). Strategic Management: M 25 Course of lectures, p. 288.

Matveyeva, E. Y. (2007). Concepts of modern natural science. Glossary of Basic Terms. Tutorial. Novosibirsk, Russia.

McAfee, A., \& Brynjolfsson, E. (2012, October). Big Data: The Management Revolution. Harvard Business Review, pp. 61-68. Retrieved from https://www.academia.edu/2662701/Big_Data_The_Management_Revolution?auto=download 
Ministry of Justice of the Republic of Kazakhstan. (2010). Decree of the President of the Republic of Kazakhstan on the State Program on Forced Industrial and Innovative Development of the Republic of Kazakhstan for 2010-2014.

Mobile phone becomes a convenient tool for payment of services and goods. (n.d.). Retrieved from http://www.ifin.ru/publications/read/1096.stm

Moskovskaya Birzha. (2015, May 6). Analytical overview of market Big Data. Retrieved from http://habrahabr.ru/company/moex/blog/256747

Nur.kz. (2015, May). Information on vacancies for May, 2015. Retrieved from http://rabota.nur.kz/

Nur.kz. (n.d.). Kcell entered the top 20 of largest companies in Kazakhstan. Retrieved from http://www.nur.kz/958699-ksell-voshel-v-top-20-krupneyshikh-kompa.html

Oracle Information Architecture: An Architect's Guide to Big Data. (n.d.). TAdviser. Retrieved from http://www.tadviser.ru/index.php

$\begin{array}{lllll}\text { Organization's } & \text { strategy. } & \text { (n.d.). } & \text { Retrieved } & \text { from }\end{array}$ http://www.lib.convdocs.org/pars_docs/refs/1/838/838_html_m2b15210c.jpg

Ozhegov, S. I., \& Shvedova, N. Y. (n.d.). Explanatory dictionary (1949-1994th ed.). Moscow, Russia.

Power, D. (2015). Using 'Big Data' for analytics and decision support. In Decision Support Systems V - Big Data Analytics for Decision Making. First International Conference, ICDSST 2015 Belgrade, Serbia, May 27-29, 2015 Proceedings.

Profit.kz. (2015, January 21). Telecommunications in Kazakhstan - the market is still growing. Retrieved from http://profit.kz/news/23041/Telekommunikacii-v-Kazahstane-rinok-raste

RAEX. (n.d.). Analytical review of the market in 2014. Retrieved from http://raexpert.ru/

Research\&Trends. (2011). Working with BigData: Main areas and possibilities. Retrieved from http://www.marketing.spb.ru/lib-research/methods/Big_Data.htm

Rouse, M. (n.d.). Business-to-business (B2B). Retrieved from http://searchcio.techtarget.com/definition/B2B

Rudberg, Y. (n.d.). Analytics. Retrieved from https://www.kcell.kz/ru

Rudberg, Y. (n.d.). Moving on to the next generation. Retrieved from https://www.kcell.kz/ru

Rybalko, S. (2005). Wireless network. Practical guidance. Moscow, Russia: COMPTEK.

Savina, I. (n.d.). Forecasts of the telecommunications market of the Republic of Kazakhstan. Retrieved from http://www.kursiv.kz/news/telekom/prognozy_2015

Schendel, D. E., \& Hatten, K. J. (1972). Business Policy or Strategic Management: A Broader View for an Emerging Discipline (371).

Sekaran, U., \& Bougie, R. (2010). Research methods for business: A skill-building approach (5th ed.). Haddington: John Wiley \& Sons.

Semyorkin, A. (2015). Bigdata: How can companies distinguish important data from unimportant ones? Retrieved from http://www.e-xecutive.ru/management/practices/

Shimko, V. I. (1995). Information technology - Instrumental basis for economic transformation in the transition to the market. "Technological equipment and materials" newsletter.

Shubin, I. I. (2006). Construction of a network of digital terrestrial television broadcasting in the Republic of Mordovia. Moscow, Russia.

Strategic Management (2017). In Planning Glossary. Retrieved from http://planningskills.com/glossary/88.php

Strickland, A. J. (2006). Strategic Management - Concepts and situations for analysis. Retrieved from http://www.elitarium.ru/

TAdviser. (n.d.). According to Gartner. Retrieved from http://www.tadviser.ru/index.php/

TAdviser. (n.d.). Matt Slocum from O'ReillyRadar. Retrieved from http://www.tadviser.ru/index.php

The concept of telecommunications technologies. Basic Definitions. (n.d.). Retrieved from http://lic1.admsurgut.ru/win/download/664/ 
The problem of limited resources. (n.d.). Retrieved from http://www.grandars.ru/

The telecom market slowed growth. (2015). Retrieved from http://kapital.kz/business

The telecommunications market in Kazakhstan is developing. (2015, January 21). Retrieved from http://kazakh-tv.kz/ru/view/business

Thompson, A., Strickland, A., \& Gamble, J. (2007). Crafting and executing strategy: Text and readings, McGraw Hill Irwin (15th ed.).

Turovets, A. M. (2014). Prospective directions for using BigData in the process of personnel management. Minsk, Russia.

Volkova, N. (2015). Business analytics for telecommunications market: Vympelcom and YandexDataFactory start cooperation in BigData.

What is an Over-the-Top Application (OTT)? - Definition from Techopedia. (n.d.). In Techopedia.com. Retrieved from https://www.techopedia.com/definition/29145/over-the-top-application-ott

Yessekeyev, K. (n.d.). Interfax-Kazakhstan. Retrieved from Informatization and Communication Agency of Kazahstan website: http://www.kcell.kz/ru

Zhukenov, R. (n.d.). National Informational technologies. Retrieved from Big Data Laboratory website: http://egov.kz/wps/portal/C

Zubarev, A. (n.d.). Business strategies of world's leading companies. Retrieved from http://cinref.ru/razdel/00800economica/01/11167.htm 